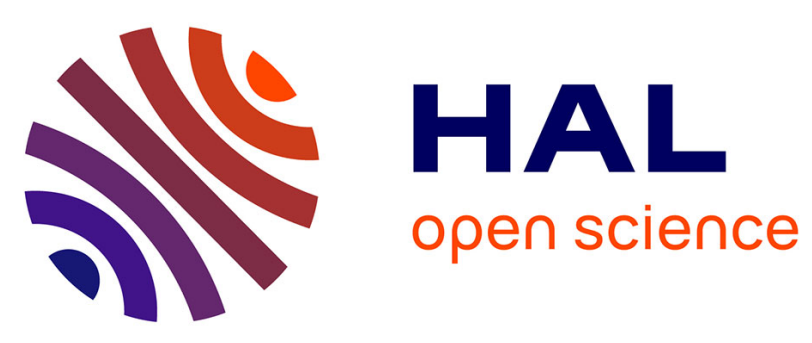

\title{
Context-Sensitive Goal Management Training for Everyday Executive Dysfunction in Children After Severe Traumatic Brain Injury
}

Agata Krasny-Pacini, Jenny Limond, Jonathan Evans, Jean Hiebel, Karim Bendjelida, Mathilde Chevignard

\section{To cite this version:}

Agata Krasny-Pacini, Jenny Limond, Jonathan Evans, Jean Hiebel, Karim Bendjelida, et al.. ContextSensitive Goal Management Training for Everyday Executive Dysfunction in Children After Severe Traumatic Brain Injury. Journal of Head Trauma Rehabilitation, 2013, 29 (5), pp.E49 - E64. 10.1097/HTR.0000000000000015 . hal-01513404

\section{HAL Id: hal-01513404 https://hal.sorbonne-universite.fr/hal-01513404}

Submitted on 25 Apr 2017

HAL is a multi-disciplinary open access archive for the deposit and dissemination of scientific research documents, whether they are published or not. The documents may come from teaching and research institutions in France or abroad, or from public or private research centers.
L'archive ouverte pluridisciplinaire HAL, est destinée au dépôt et à la diffusion de documents scientifiques de niveau recherche, publiés ou non, émanant des établissements d'enseignement et de recherche français ou étrangers, des laboratoires publics ou privés. 
Context-sensitive Goal Management Training for everyday executive dysfunction in children after severe TBI.

AUTHOR NAMES AND HIGHEST ACADEMIC DEGREE

Krasny-Pacini Agata ${ }^{1,4}$ MD, Limond Jenny ${ }^{3}$ PhD, Evans Jonathan ${ }^{3}$, PhD, Hiebel Jean ${ }^{1}$ MD, Bendjelida Karim ${ }^{5}$ MD, Chevignard Mathilde ${ }^{2,4}, \mathrm{MD}, \mathrm{PhD}$

Affiliations:

1. Institut Universitaire de Réadaptation Clemenceau-Strasbourg, 45 bd Clemenceau, 67082 Strasbourg, France Paediatric Department and Hautepierre Strasbourg University Hospital, Strasbourg. France

2. Rehabilitation Department for Children with Acquired Brain Injury, Hôpitaux de Saint Maurice, 14, rue du Val d'Osne, 94410 Saint Maurice

3. Mental Health and Wellbeing, Institute of Health \& Wellbeing, University of Glasgow, Gartnavel Royal Hospital, 1055 Great Western Rd, Glasgow G12 OXH , Scotland, UK

4. ER 6-UPMC, University Pierre et Marie Curie - Paris 6, Pitie-Salpêtrière Hospital , Paris, France

5. EMOI-TC 68, Hôpital du Hasenrain, 87 avenue d'Altkirch 68051 MULHOUSE CEDEX, France

Corresponding author : Agata Krasny-Pacini agatakrasny@yahoo.com; 0033671284152

Institut Universitaire de Réadaptation Clemenceau-Strasbourg, 45 bd Clemenceau, 67082 Strasbourg, France

\section{CONFLICTS OF INTEREST}

The authors report no declarations of interest.

\section{DISCLOSURE OF FUNDING RECEIVED FOR THIS WORK}

This study was supported by scholarships, from the "SOFMER" (French Society of Physical and Rehabilitation Medicine), the "SFERHE" (French Research Society against Children's handicap) and the "Fondation Gueules Cassées".

\section{ACKNOWLEDGMENTS CREDITS OR DISCLAIMERS}

We are grateful to Brian Levine, lan Robertson and Tom Manly for providing us with GMT materials and to Leigh Schrieff, Kevin Thomas and Clare Corbett for providing us with their pilot pediatric version of GMT. We would like to thank all rehabilitation teams who participated in the recruitment of children for the study and especially the children's department of Clemenceau University rehabilitation Center in Strasbourg; Marilyne 

the illustrations of the theoretical modules and Arnaud Roy for providing us with the FEE battery and for his useful advice. Finally we would like to thank the two anonymous reviewers for their valuable and constructive feedback on the paper's previous drafts.

\section{Context-sensitive Goal Management Training for everyday executive dysfunction in children after severe TBI.}

\section{ABSTRACT}

Objectives: To assess the effectiveness of a metacognitive training intervention, based on an adapted Goal Management Training (GMT) and on Ylvisaker's principles, on three activity domains of executive functions: (1) prospective memory (PM) performance in ecological setting, (2) complex cooking task management, (3) daily executive functioning (EF) at home and at school. Participants: Five children aged 8-14, who were 3-11 years post severe traumatic brain injury (TBI), experiencing severe EF difficulties in daily life. Design: Single-case experimental design, and assessment of EF twice prior to intervention, post-intervention, 3- and 6-months post-intervention. Progress was monitored by a weekly ecological PM score. The effect on EF was assessed using the Children's Cooking Task (CCT). Transfer to the child's natural context was assessed by parental and teacher questionnaires and Goal Attainment Scaling. Results: All children improved on the measure of PM and on questionnaires of daily EF. Two children improved on the CCT but returned to their pre-intervention level in a novel cooking task at follow-up. School personnel and parents' participation in the program was low.

Conclusions: It is feasible but challenging to use GMT in children with TBI. Further research is needed in relation to how to promote generalization and how to increase the involvement of the child's "everyday people" in the intervention.

Keywords: Executive functions, Prospective memory, Traumatic/Acquired brain injury, child, intervention, ecological, daily life activities, Goal Management Training

\section{INTRODUCTION}

JHTR PGMT 2013 
Executive functions (EF) are a collection of related but distinct abilities that allow individuals to engage efficiently in intentional, goal-directed problem-solving actions ${ }^{1,2}$ through conscious and effortful processing ${ }^{3}$ and to adapt to new situations in the real world ${ }^{4}$. Executive functioning (EF) deficits are a frequent consequence of traumatic brain injury (TBI) ${ }^{5}$. TBI outcome is predicted by executive functioning level ${ }^{6}$.

There is a lack of validated methods for EF rehabilitation in children ${ }^{7,8,9}$, although some general rehabilitation principles have proven to be useful . Ylvisaker ${ }^{10}$ emphasized two principles : (1) the key role of parents and of all the 'everyday people' surrounding the child in the "cognitive coaching" of their child (See Braga"1 and Wade ${ }^{12,13}$ for examples of family-delivered interventions in TBI); (2) the necessity of a "context-sensitive" approach $^{14}$, embedded in functional routines of everyday life and using meaningful activities rather than decontextualized exercises.

In current clinical practice, four types of approaches are used to help children with their EF difficulties, though each has its limitations: (1) Providing environmental support and compensatory aids (e.g. use of electronic prompting devices) - though only a restricted number of situations lend themselves to such an approach; (2) Training component EF skills (e.g. repeated exercises aiming at changing the brain's working memory capacity for example) - though transfer to natural contexts and generalization to untrained activities effects of this approach have rarely been demonstrated ${ }^{14} ;$ (3) Training children on specific goals (e.g. if preparing a schoolbag is problematic, the child will be trained on this specific activity until the goal is achieved) - though generalization to similar goals in different situations (e.g. preparing a suitcase for holidays) is often not achieved; (4) Providing children with metacognitive strategies applicable to a variety of everyday situationswhilst this is effective in some adults after $\mathrm{TBI}^{15}$, there is little evidence that metacognitive training is effective for children with a dysexecutive syndrome post $\mathrm{TBI}^{16}$, though research on children with other forms of brain injury suggests it may be a useful approach ${ }^{16} 17$.

Goal Management Training $(\mathrm{GMT})^{18}$ is one of the most studied metacognitive training programs, of which many variants exist ${ }^{19}$. GMT includes self-instruction strategies, self-monitoring exercises, metacognitive strategies aimed at improving planning, prospective memory and hierarchical goal management, mindfulness practice exercises, stories promoting discussion about executive dysfunction in daily life, and homework assignments 
(See Levine et al. ${ }^{20}$ for a more detailed description). GMT was developed from Duncan's theory of "goal neglect"21,22, which suggests that dysexecutive patients are impaired in the construction and use of "goal lists", necessary for goal-directed behavior. They do remember the intended goal but tend to lose sight of it as they progress through a task leading to a prospective memory failure. Prospective memory (PM) (remembering to carry out intended actions) tasks require retrospective memory to remember the task, but depend on $\mathrm{EF}^{23}$ for successful goal maintenance, retrieval and implementation at the right moment. PM depends upon frontal lobe integrity ${ }^{24}$, with a key role for rostral prefrontal cortex $(B A 10)^{25}$. In typically-developing children aged 6-12, performance on EF tasks such as planning and switching ${ }^{26}$, working memory ${ }^{27}$, and inhibition ${ }^{28}$ is correlated with $\mathrm{PM}^{29}$. PM problems are reported as a major concern for the parents of children with $\mathrm{TBI}^{30}$. $\mathrm{PM}$ is impaired in children with $\mathrm{TBI}{ }^{31,32}$ compared to children with orthopedic injuries, even after cues are given ${ }^{33}$, and even under strong incentive conditions ${ }^{34}$.

The primary aim of this study was to assess the feasibility and effectiveness of implementing a metacognitive training intervention, based on an adapted form of Goal Management Training (GMT) and on Ylvisaker's rehabilitation principles, in three domains: (1) prospective memory performance, (2) complex cooking task management (3) daily executive functioning at home and at school. Secondary aims were to determine if the effects of such a metacognitive training generalize enough to help children to (1) achieve personalized, untrained, goals and (2) manage a demanding novel task that requires EF's.

\section{METHODS}

Participants. The study was approved by the ethics committee of Pitié-Salpêtrière University Hospital in Paris, France. Informed parental written consent and participation assent were obtained for all participants prior to initiating any procedure.

Inclusion criteria were: (1) severe TBI (initial Glasgow Coma Score lower than 9); (2) sustained at least 2 years previously; (3) children attending one of the two participating rehabilitation departments; (4) aged 8-14; (5) evidence of a dysexecutive syndrome on neuropsychological assessment performed at least two years post injury; (6) parental report of executive functioning difficulties in daily life. 
Exclusion criteria were: (1) diagnosed learning disabilities, neurologic or psychiatric condition prior to TBI; (2) severe intellectual disability; (3) insufficient French language level of the child or of his/her family.

Characterization data included classical standardized tests from the Wechsler Intelligence Scale for Children $(\text { WISC-IV) })^{35}$, from the Children's Memory Scale ${ }^{36}$ and a French battery of EF for children: "Fonctions Exécutives Enfant" battery $(\mathrm{FEE})^{37}$. FEE has a much larger normative data than any other EF test available in French. Each child participating in the intervention was compared to a sample of controls matched for sex, age and socioeconomic status from the FEE database, using Crawford's method ${ }^{38}$ with one-tailed probability ${ }^{39}$ taking $\mathrm{p}<0.05$ criteria for significance.

\section{Intervention}

The intervention was inspired by Goal Management Training ${ }^{18}$ (GMT) but extended to follow Ylvisaker's principles of involving "everyday people" in the child's social network in the cognitive coaching of the child and using a context-sensitive approach prioritizing functional ecological activities.

Prior to the intervention, parents participated in a two to three hour informal interview during which the following were discussed: 1) the child's daily life difficulties at home and at school; 2) program content and key GMT concepts; 3) the need to apply the metacognitive GMT techniques at home and at school. An emphasis was put on the key role parents played for the success of the intervention.

The intervention comprised of: (1) GMT theoretical modules and between session "missions" (promoting GMT use at home and at school); (2) practical modules in which children practiced GMT content in meaningful activities; (3) an "everyday people cognitive coaching guide". The materials included PowerPoint slides, a workbook, posters for home and school use, mission sheets and the cognitive coaching guide. The 15 modules (theoretical modules+ meaningful activities) of the intervention required 15-20 hours to be completed, and were administered individually over a four to six-month period on a weekly basis, either in a rehabilitation centre or at home.

(1) Theoretical modules were derived from the adult GMT PowerPoint Manual ${ }^{20}$ developed by Levine, Robertson and Manly, that has already been used (with minor changes) in children ${ }^{40}$. A new, shorter, colourfull 
version was created for the intervention to make materials child-friendly, age-appropriate, enjoyable and simpler. For example, "slips" (referring to slips of attention) became "Oops errors". "To Do lists" and the "mental blackboard" were combined in a unique "note book" concept in order to explain to the children how a real paper note book can help them not to overwhelm their "mental notebook". Discussion about EF failures in daily life was triggered through illustrated stories relating to school and leisure activities. In each module we included a prospective memory task to be performed during the session (e.g. when you see a slide with $\mathrm{X}$ you do Y) to encourage discussion about PM failures at the end of each session. The content-free cue "Look into your mental notebook" was used as a prompt when children failed PM tasks. Throughout the training period children had to complete "mission sheets", inspired from GMT between-session assignments. These were of three types, introduced progressively: 1) monitoring Oops errors, their consequences and factors influencing their occurrence; 2) listing occasions on which the child used a metacognitive strategy of his/her own or from the program with success; 3) identifying situations where a stepwise processing approach can be used in order to manage a goal (preparing the school bag, preparing a sandwich).

(2) Practical modules served to practice GMT content in meaningful activities (Ylvisaker's Content-sensitive principle): cooking of various meals, route finding, searching for information, poster making, photo ordering. This was an explicit generalization training that was aimed to show the children that GMT metacognitive strategies are applicable to many situation in life where their EF impairment may impede success, and to promote the use of these strategies to personal (present and future) goals and untrained activities ${ }^{41}$. The activities involved planning, strategy generation, following steps, and monitoring of actions. Difficulty increased as children progressed in the program. Similarly to the theoretical modules, the meaningful activities contained naturally occurring prospective memory tasks to allow discussion about PM difficulties in real activities (e.g. checking regularly if the first set of finger biscuits is cooked while preparing the next). The trainer guided the children when needed, using non-specific prompts and general cues. Explicit help was only given if these were not sufficient. At the end of each activity, the child was invited to review his/her performance using the "mission" sheets, identify Oops errors and any effective strategy that had helped in the task, and to think about situations in real life where the same kind of strategy may be useful. The child always took the 'product' 
of his/her activity (e.g. crepes) home to increase motivation from the praise s/he received at home. Moreover, the 'product' was expected to remind the parents about the child's program.

(3) To encourage transfer to the child's natural contexts, we tried to involve the child's 'everyday people' as cognitive coaches for their child. Everyday people were parents, teachers, school assistants and any adult the parents identified as a potential cognitive coach (baby-sitter, student helping the child with homework). A letter presenting the program was sent to the child's teacher and school assistant (SA), explaining briefly TBI executive problems and their implications, and asking the teacher and the SA to participate by applying GMT at school. The intervention content was not explained orally. We asked for a contact e-mail and a telephone contact to discuss the child's difficulties and set realistic goals on goal attainment scales. The letter was sent a second time after one month as the first yielded few responses, so we had responses from at least one school staff member per child. Other potential 'everyday people' identified by the parents were sent a similar letter. Twice a month all 'everyday people' who agreed to participate received one chapter, two-pages long, of a "Cognitive Coaching Guide" that was created for the intervention. The guide was colorful, using the same drawings, diagrams and analogies as the theoretical modules, explaining the rehabilitation content and suggesting how to apply metacognitive strategies at school and at home. The intervention was organized in a way that each metacognitive strategy was (1) first introduced during a theoretical module, (2) then practiced on a meaningful activity and (3) lastly introduced to everyday people. They were sent the corresponding chapter of the coaching guide that described the activity for which the child had already practiced the strategy, and suggested other activities to which it could be applied (see supplemental digital data for examples). Through this guide, everyday people were encouraged: (1) to use non-specific prompts for PM failures ("look into your mental note book") rather than specific instructions ("you need to feed the dog") or negative sentences ("you've forgotten to feed your dog again!"); (2) to promote strategy generation instead of giving the solution to their child, consistent with Ylvisaker's aim of "helping the child to become a strategic thinker"10; (3) to prompt and help the child to fill in his/her "mission sheets" regularly; (4) to practice goal identification ("state your goal") and stepwise processing in daily activities (preparing schoolbag, table setting). Parents were explicitly asked to go through the metacognitive strategies of the cognitive coaching guide and to sign the 
child's GMT workbook every week. The 'everyday people' were not requested to participate in the rehabilitation session, but were advised that the therapist was available if they had any questions.

Qualitative data about the program. Throughout the sessions, the therapist recorded (1) how the child reacted to the intervention content; (2) if the metacognitive strategies were easily understood and used; (3) if the child seemed aware of his/her EF difficulties during discussion and performance of meaningful activities; (4) if the "mission sheets" were filled-in between the sessions.

Study design. Intervention effectiveness was assessed in two ways: (1) A Single-Case Experimental design $(\mathrm{SCED})^{42,43}$, with repeated ecological measurement of prospective memory was used to monitor progress throughout the intervention; (2) pre-post measurement of EF with two baseline assessments 4-8 weeks apart (B1 and B2), and three post-intervention assessments: immediately after the intervention (R1), and at three (R2) and six months (R3) to assess maintenance of effects. Baseline was expected to be stable as children had sustained their TBI at least two years earlier, minimizing chances of spontaneous recovery during the study. The pre-post measurement served to capture the key issues of EF rehabilitation, namely: (1) EF performance in ecological tasks; (2) transfer of training effects to natural contexts; (3) generalization to untrained tasks; (4) need for novelty for a task to truly test "executive" functions.

\section{Outcome Measures}

Repeated measures of prospective memory (PM) performance - SCED design: We monitored the effectiveness of the program through a weekly score on a time-based PM task. The PM task was inspired by the Fish et al. phone call task ${ }^{44}$ that has recently been used in children ${ }^{45}$. Three times a week, children had to look up the day's Saint on a calendar (e.g. $24^{\text {th }}$ June is Saint John's day), and send it to the therapist at an agreed target time, either as a text message, an e-mail or a phonecall. The child was awarded three points if correct information was given within one hour of the agreed time, two points if within the day, one point if on a different day and zero points if the child completely forgot about the task. The retrospective memory component was controlled for by checking at each session that children remembered the task and agreed times. Parents were given the timings in case the child wanted to check the target time. To encourage use of mental strategies, children were asked not to use cues such as alarms, or pre-programmed text messages. 
Parents were instructed not to give any cues or help to complete the task. The three target days and times were chosen individually for each child with the parents before the first assessment to ensure: (1) that the child was easily available for the task (i.e. not during school time or leisure activity); (2) that it didn't disturb family routines (e.g. bedtime); (3) that the time didn't correspond to a regular activity that could act as a cue (e.g. TV show); (4) that timings respected the following common rules for all the children: non-consecutive days, one week-end day and two school days, except the day of the intervention and different target time on each of the three days. As in Fish et $\mathrm{al}^{44}$, days when the tasks had not been performed for another reason than PM failure, were not used in the analysis (medical appointment at target time, no internet connection during a week-end outing); therefore the total score was expressed as a percentage of total possible points that week.

"Children's Cooking Task" (CCT) - pre-post ecological measurement of EF: As the aim of this study was to improve EF in daily life, assessment included an ecological ${ }^{46}$ test of EF, called the Children's Cooking Task $(\mathrm{CCT})^{47,48}$. In the CCT, children have to prepare a real chocolate cake and a fruit cocktail following a structured, photo-cued, child-friendly recipe contained in a cookbook including distractors. The task has been shown to be highly sensitive to executive dysfunction in TBI as it is novel, challenging, open-ended, and requires multiple goal management and innovative higher level strategies to succeed. The Children's Cooking Task (CCT) has good inter-rater and test-retest reliability, high internal consistency, as well as good discriminant and concurrent validity ${ }^{47}$. It can be performed from the age of 8 . Scoring is based on the number of errors, including omissions, additions, commentaries, substitution and estimation errors. Normative data is not yet available. Therefore raw scores were used to track individual child changes. The number of errors in CCT made by each child was compared to the number of errors made by age matched healthy controls, extracted from unpublished data ${ }^{49}$.

Questionnaires - pre-post measurement of EF in natural contexts: Ultimately, the aim of any cognitive rehabilitation intervention is to allow a transfer of learned skills to the natural context of the child ${ }^{10}$, and this was particularly important to assess because metacognitive training aims at providing children with strategies they can apply to many tasks in their natural context. This was assessed through two questionnaires of EF: (1) the Behavior Rating Inventory of Executive Functions (BRIEF) questionnaire ${ }^{50,51}$, completed by both parents 
(transfer to home-context) and teachers (transfer to school-context); (2) a cognition subscore derived from the Dysexecutive Questionnaire for Children (DEX-C $)^{52}$ that was completed by parents only. The BRIEF assesses eight domains of executive functioning in the real world, which give together a Global Executive Composite (GEC) score. Higher scores correspond to increased EF difficulties in daily life. A T-score superior to 65 is defined as the clinical range. The BRIEF has large normative data for children aged 5 to 18 , high internal consistency ${ }^{53}$, good validity ${ }^{54}$ and good test-retest reliability ${ }^{53}$ although parent-teacher agreement is only moderate ${ }^{53}$. It is the most commonly used questionnaire of executive functions and seems to be sensitive to deficits in executive functioning in children with $\mathrm{TBI}{ }^{54,55,56,57}$. Its relationship with common EF cognitive tests is however inconsistent. DEX-C is a 20 item questionnaire, probing four broad areas of EF difficulties (emotional/personality, motivational, behavioural and cognitive) and is part of the "Behavioural Assessment of the Dysexecutive Syndrome for Children" ${ }^{52}$. Higher Z-scores correspond to increased cognitive difficulties relating to EF. DEX-C has less evidence regarding psychometric properties ${ }^{52}$. However the cognitive subscale of DEX-C completed by parents has a high correlation with the (Children's Cooking Task) CCT score ${ }^{47}$, and therefore this subscale together with the CCT were expected to detect improvement in cognitive EF impairment, which the BRIEF might not capture.

\section{Goal Attainment Scaling (GAS) - pre-post measurement of generalization (metacognitive strategy use in}

untrained tasks): GAS $^{58,59}$ was used as a generalization measure to assess if a child who has applied metacognitive strategies to meaningful activities in a rehabilitation setting is capable of applying those strategies to untrained tasks that are judged to be problematic for him/her by his/her everyday people. EFrelated problems reported by the child, parents and school staff served to elaborate personalized goal attainment scales (GAS) for each child. These GAS goals were not trained specifically but children were repeatedly encouraged to apply metacognitive strategies to daily life. We also used "general" GAS for metacognitive strategy use and GMT application (see table 3 in results section). Themes of "general" goals were similar for all children, but the initial levels and expected outcome levels were specific to each child, taking into account children's age and possibilities. The detailed procedure for goal selection, GAS elaboration and GAS levels adjustment are described in supplemental digital data. GAS scores were used to calculate a global T-score for each child, using Kiresuk's formulae (see ${ }^{58,59}$ for details of GAS methodology). A T-score of 50 
meant that the goals were overall attained as expected, and $>50$ that goals were attained better than expected.

\section{"Christmas biscuits task" - measurement of adaptation to novelty, performed once only at the end of the}

intervention: $\mathrm{EF}$ outcome measures need to be novel to really capture $\mathrm{EF}^{60,61}$. When the same task is repeated after intervention, it is more "familiar", which can make it less demanding on EF 62,63 . Familiarity effects increase when patients are tested on several occasions (as it is the case in our design for CCT). To get a "purer" EF measure post-intervention ${ }^{63}$, we developed a parallel form of the Children's Cooking Task (CCT) for assessment at R3, involving the same number of steps and ingredients but requiring different types of ingredients and procedures. This version has no established psychometric properties. Children had to bake "Christmas biscuits". Whilst both tasks required cooking, as children were not experienced cooks, a new recipe could not be viewed as a familiar task.

Controlling for confounding factors. At the beginning of the program everyday people were not informed of exactly when the intervention component would commence: from the first interview onwards all children were seen weekly, whereas the intervention started only 5-8 weeks later. We hoped to control in this way for parent's enthusiasm for a novel rehabilitation program, which was expected to be reflected by an improvement between B1 and B2 in this study design. The intervention effect was measured comparing post intervention results (R1, R2 and R3) to the second baseline (B2), as this was considered a "purer" baseline eliminating the enthusiasm and novelty effect. Inconsistent answers to the BRIEF questionnaire were detected by computing the inconsistency score described in the BRIEF manual (a score $>9$ being a threshold to consider the questionnaire unreliable because of contradictory answers on special items serving to assess consistency of answers). Furthermore, the intervention did not significantly change the amount of time spent in rehabilitation: all children had already been attending the outpatient department for half a day a week for many years (including sports, group games and group discussion to promote socialization and language pragmatics for PB,CS,RK; analytic psychotherapy for PB, paper-and pencil neuropsychological exercises aiming at improving attention for IP) therefore the effect of the potentially confounding factor of time spent with therapist was considered likely to be negligible. 
External investigator post-intervention interview. After the intervention, an external interviewer, who had neither been involved in the rehabilitation nor the research team called all the everyday people involved in the program. A structured interview focused on how they perceived the program, their views on applying cognitive coaching at home and at school, clarity of the cognitive coaching guide, how children reacted to the intervention and if they thought their child had improved in various domains (autonomy, school results...) even if it was a domain not included in GAS and questionnaires. The interview contained embedded questions aimed at quantifying how much the everyday people participated in the cognitive coaching and at checking if they understood the concepts that were explained to them in the cognitive coaching guide. They were asked for examples of metacognitive strategies they could recall, situations they applied them to, and were asked how often they managed to go through the child's workbook together, and if GMT posters had been hung at home. Feedback from the child was obtained informally from the first author conducting the intervention, because answering to an unknown external investigator on the phone was considered age-inappropriate.

Statistical analysis and effect size (ES) calculation. The Saint's day task (SDT) PM scores were visually analyzed on time series graphs comparing baseline (weeks 1-4), with intervention (weeks 5-18). A two-standard deviation band (2SDB) was determined for each child based on the standard deviation of the four baseline points. Gottman and Leiblum's criterion was used: the probability that two consecutive points fall outside the 2SDB is $<0.05$. (see for details ${ }^{42}$ ). Trends were detected by celeration lines, using the Split Middle Trend line procedure $^{42}$. To obtain the magnitude of effect, the "nonoverlap of all pairs" (NAP) method was used ${ }^{64}$, through SPSS software. For the other outcome measures, an intervention effect size (ES) was calculated for each child from B2 to R1, R2 and R3 as a standard difference between T-scores divided by 10 for the BRIEF and as a standard difference between Z-scores for the DEX-C Cognition scale. For the CCT, ES was obtained by dividing the score difference by the standard deviation of all five CCT scores of the child. Furthermore, because the CCT inevitably has a practice effect as the recipe becomes more known, which could account for improvement throughout the trials, we readjusted ES by subtracting the practice effect of each child (score change between B1 and B2 being considered as the practice effect for that child). ES were interpreted subjectively with reference to Cohen's guidelines ${ }^{65}: 0.2=$ small; $0.5=$ medium; $08=$ large. 
Five children, aged 8 to 13 years met the inclusion criteria (PB, CS, RK, IP, YR). All had sustained severe TBI at an early age, three to eleven years before the study and had a highly complex family situation. All had specialized schooling, either attending a special support class or having a school assistant. Characteristics of the participants are summarized in table 1 . All children had a severe dysexecutive syndrome on paper-and-pencil EF tests (see table 1bis in Supplemental Digital Content), on CCT (see B1 and B2 scores in Figure 2), and (apart Content).

\section{table 1 : attached at the end of the paper} from child IP' BRIEF score) on EF-questionnaires (see B1 and B2 in Figures 3 and 4). In contrast they were not impaired in reasoning abilities (apart from CS) or retrospective memory (see table 1ter in Supplemental Digital

One child (YR) dropped out of the study after 4 sessions. YR seemed to be unaware of his impairments, and decided that he no longer wanted to be involved in any rehabilitation. His challenging behavior (see Table 1) and school absconding were the main issues at the time of the study. He was however included in this pilot study initially because it was hoped that an intervention focusing on meaningful activities might be accepted by YR in contrast with all the other rehabilitation and school support he refused.

Qualitative data about the program. The intervention appeared to be feasible to implement and it was reported that children enjoyed it, especially the meaningful activities and stories used in the theoretical modules. Most GMT concepts were understood by the children, although examples of personal cognitive failures were difficult to obtain. Interestingly, children seemed to consider the metacognitive strategies as exercises to practice rather than something that could be applied to other tasks. As such, they would use the strategies on theoretical modules (e.g. pausing regularly and stating the goal while sorting cards with an embedded PM task) but were reluctant to apply them to more complex and ecological activities such as cooking, judging the strategies as an additional task per-se and demonstrating no consistent application of strategies in the meaningful activities. Only the 14 year-old RK, probably the most aware and the most impaired in daily life, actually engaged with the techniques and used them whenever he noticed task 
similarities. CS seemed to understand only a few GMT concepts and metacognitive strategies. IP and PB seemed to lack awareness of impairments and reported not finding the intervention useful, but found the program was fun and they participated willingly.

Repeated PM measures. The Saint's Day Test was performed by 3 children. IP, aged 8 , did not complete the task as he was not familiar with mobile phones, did not know how to use the internet and making a phone call to an unfamiliar person was not age-appropriate. YR dropped out of the study. Weekly PM score changes over time are shown in Figure 1. During baseline, none of the children reached a score of 50\%. Using a two-standard deviation band (2SDB), all children showed statistically significant progress, as all had at least two consecutive points outside their 2SDB. The best progress seemed to be made by PB. Unfortunately, when her performance was reaching $100 \%$ on week 12 , she lost the charger of her mobile phone and her parents did not replace it until the end of the study giving only a medium effect (NAP $=0.47[0.12-0.81])$. CS began to make progress on the SDT only by week 8 . She maintained performance until school holidays (week 17) when her performance dropped momentarily to 0 (overall medium effect; NAP $=0.74[0.50-0.98]$ ). RK had a very variable performance but a strong effect of intervention (NAP $=0.87[0.713-1])$. The use of the following strategies to manage the task were reported by parents and/or children: stopping all activity up to one hour before the target time and watching the clock (RK), using cues such as the view of her computer (CS).

Figure 1-3: Saint day task (SDT): prospective memory score changes over time

Note: The vertical line correspond to the beginning of the intervention. Arrows correspond to split-middle celeration lines. Dashed lines correspond to +2 and -2 standard deviation band 
Child PB

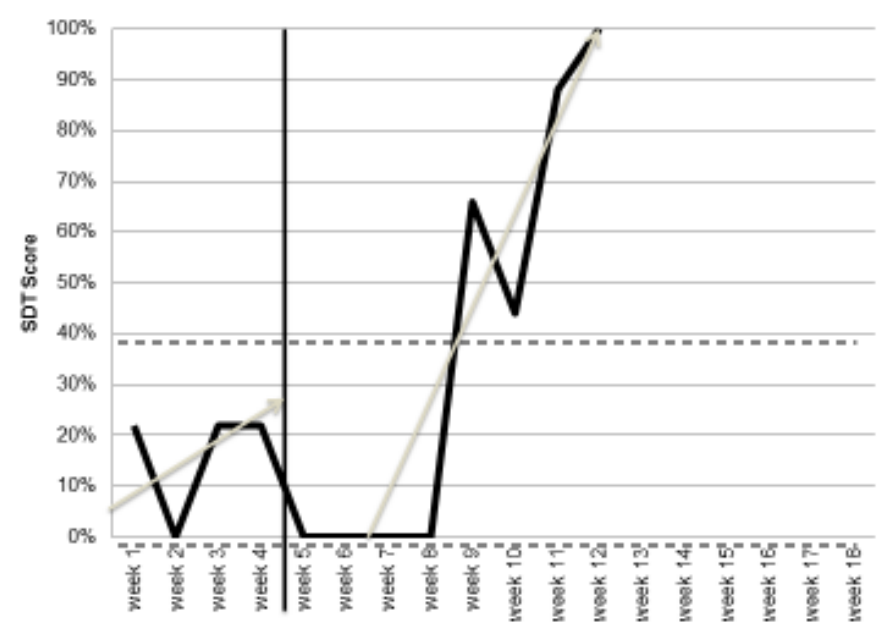

Child CS

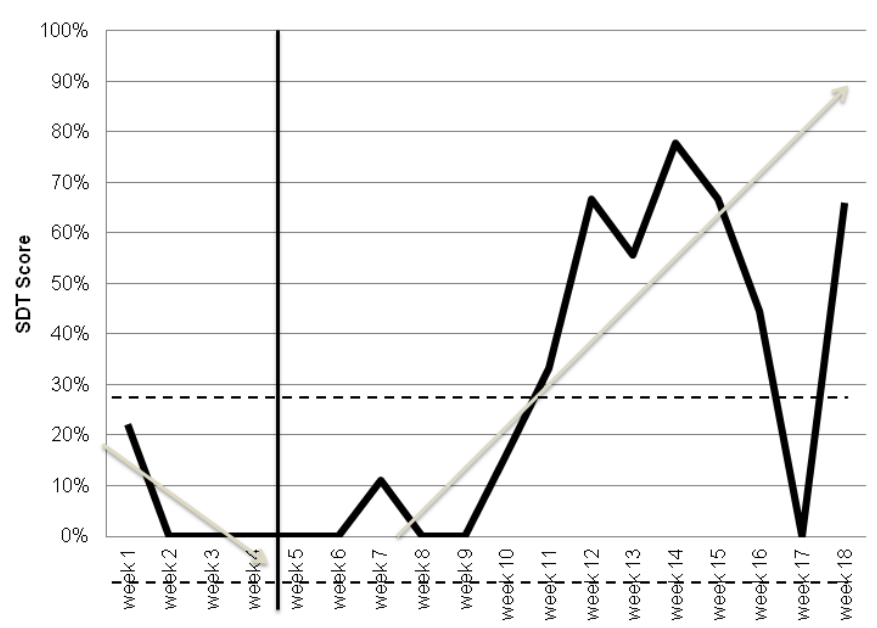

Child RK

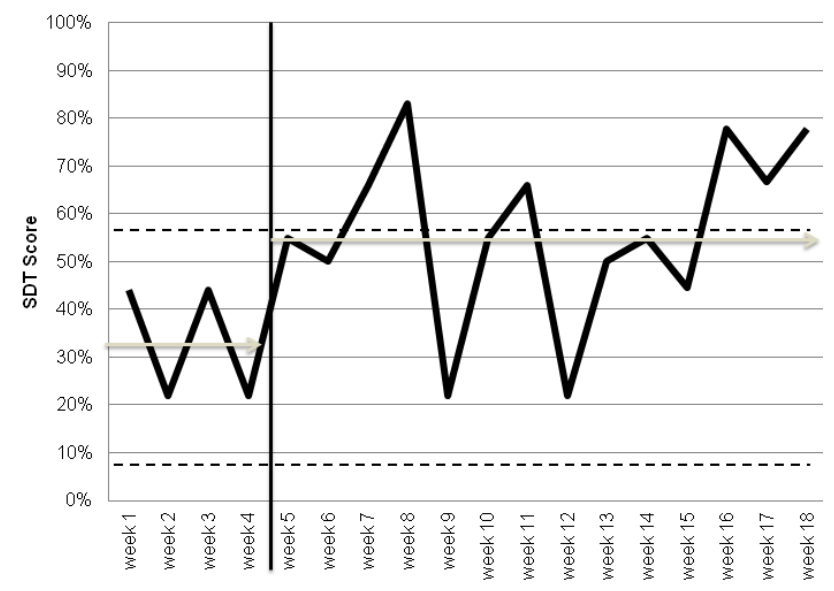


Complex Cooking Task Management: Ecological EF test “Children's cooking task" and its parallel form

("Christmas Biscuits"). All children were very impaired on the Children's Cooking Task (CCT), scoring from 3

(CS) to 25 (IP) standard deviations below age matched controls. RK and PB required help from the examiner to finish the task, IP completed the task with nearly 200 errors, and failed the task. CS's errors were mainly commentaries/questions on every action she undertook but she successfully finished the task.

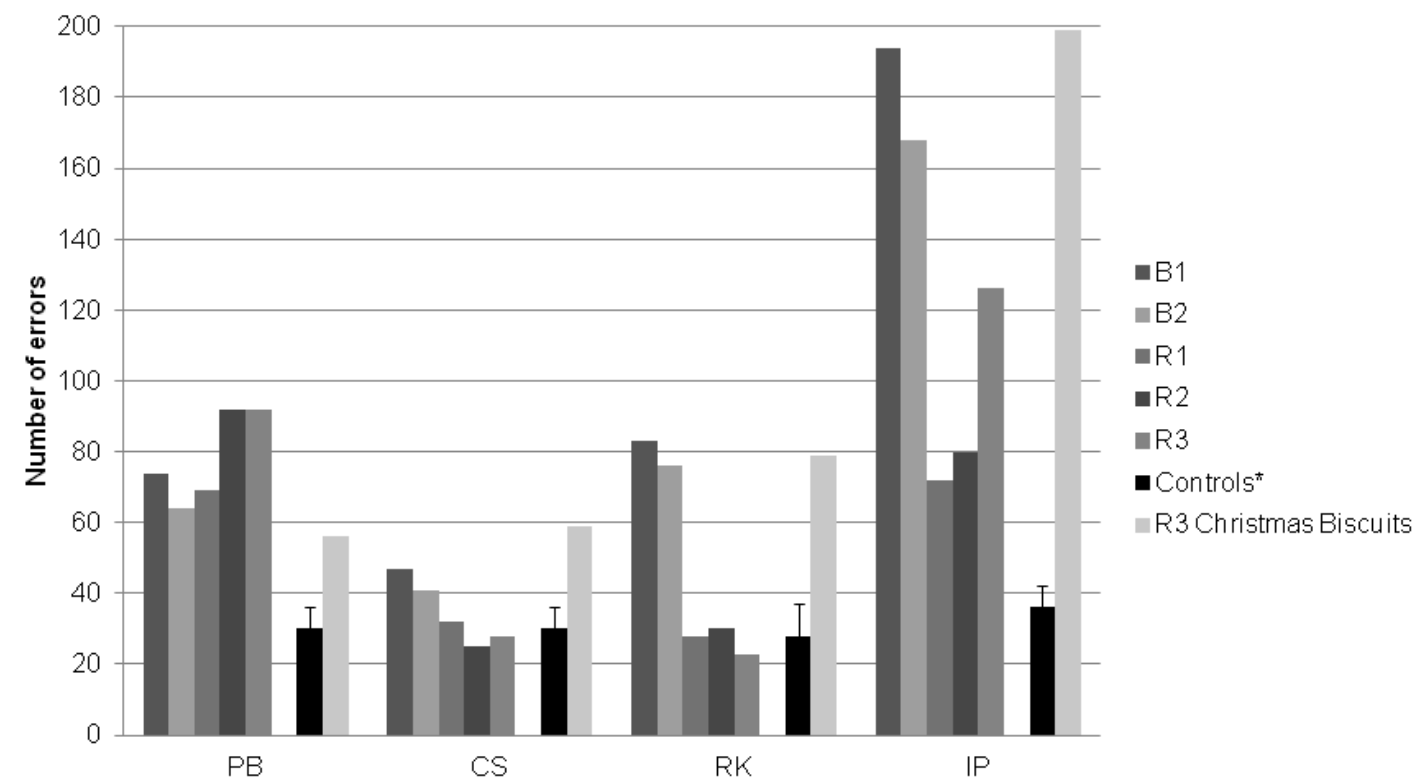

Figure 2 : Number of errors in the Children's Cooking Task (CCT): changes over time ( ${ }^{*}$ age-matched controls, $n=8$ to 13 per child). Note 1 : $B 1$ and B2: first and second baseline assessments; R1, R2, R3: assessments performed at 0,3 and 6 months post-intervention. Note 2: : In CCT, errors include action errors, as well as commentaries/questions.

Changes in the number of errors from baseline to post intervention and follow-up for each child are presented in Figure 2. During baseline, all children showed some practice effect between B1 and B2. After intervention, PB increased number of errors. Interestingly, she was so focused on not repeating the errors from her previous trial, that she often skipped whole recipe steps, and thus forgot more ingredients/steps throughout the trials. Furthermore from trial to trial, PB seemed more confident each time, and stated how well she knew the recipe and how easy it would be. For CS, the decrease of errors from B2 to R1 had a small effect size (see table 2).

Conversely, RK and IP significantly decreased the number of errors after the intervention with large effect sizes, RK showing a performance similar to controls after intervention and IP improving from 25 to 6 SD compared to 


\begin{tabular}{|c|c|c|c|}
\hline & ES at R1 & ES at $\mathbf{R 2}$ & ES at R3 \\
\hline \multicolumn{4}{|c|}{ Children's Cooking Task } \\
\hline PB & -1.15 & -2.90 & -2.90 \\
\hline CS & 0.33 & 1.09 & 0.76 \\
\hline RK & 1.42 & 1.35 & 1.59 \\
\hline IP & 1.31 & 1.16 & 0.30 \\
\hline \multicolumn{4}{|c|}{ Parental BRIEF } \\
\hline PB & 0.5 & 0.2 & 0.1 \\
\hline CS & 0.9 & 1.3 & 0.4 \\
\hline RK & 0.1 & 0.1 & -0.1 \\
\hline IP & 1.2 & 0.8 & 1 \\
\hline \multicolumn{4}{|c|}{ DEX-C Cognition Score } \\
\hline PB & 1.33 & 2.00 & 2.33 \\
\hline CS & 0.67 & 1.00 & 1.33 \\
\hline RK & 0.67 & 0.00 & -0.67 \\
\hline IP* & 2.00 & 1.67 & 1.84 \\
\hline IP compared to B1* & 0.67 & 0.33 & 0.50 \\
\hline \multicolumn{4}{|c|}{$\begin{array}{l}\text { Cohen's rating of effect size: } 0.2=\text { small; } 0.5=\text { medium; } 0.8=\text { large. } \\
\text { *Because IP's DEX-C Cognition Score at B2 was deviant (see figure } 4) \text {, we also report here ES comparing post } \\
\text { intervention outcomes to his best baseline score }(B 1)\end{array}$} \\
\hline
\end{tabular}

controls. RK clearly used the metacognitive techniques taught in the intervention while performing the CCT

(checking he finished a step before moving to the next, saying "Stop!" and thinking before adding a new ingredient...). Effects were totally maintained at 3 and 6 months for RK whereas effect progressively diminished at 3 and 6 months for IP. However when using a completely different and unknown recipe at R3 (Christmas Biscuits) all children returned to their initial number of errors.

Table 2: Outcome measures Effect Sizes (ES) comparing B2 to R1, R2 and R3.

Note: R1, R2, R3: assessments performed at 0, 3 and 6 months post-intervention; BRIEF: Behavior Rating Inventory of Executive Functions; DEX-C: Dysexecutive Questionnaire for children

Transfer to natural contexts. At baseline, all children but one (IP) scored in the clinical range (T-scores > 65) for Global Executive Composite (GEC) scores on parental and teacher BRIEF questionnaires. Transfer to homecontext: All parental scores were consistent (inconsistency score <9). Immediately after the intervention 3 children (PB, CS, IP) showed a decrease on parental BRIEF scores (see Figure 3), reflecting possibly less executive dysfunction in daily life at home. Effect sizes are reported in Table 2. All but one child (IP) showed a 
decrease on DEX-C cognition sub-scores between the two baselines that was considered to be the enthusiasm effect we had expected due to intervention novelty. However the decrease was accentuated much further after the intervention for all children and continued to decrease at three- and six-month follow-up for PB and for CS with large effect sizes (2.33 for PB and 1.33 for CS, see table 3). Transfer to school-context: Teacher BRIEF scores remained stable for RK and CS, were unreliable for PB and for IP (inconsistency index >9), meaning it was not appropriate to draw any reliable conclusions on EF in the school context for these children, although PB's BRIEF seemed to show significant improvement. PB was reported to have made excellent progress at school on school academic reports.

Figure 3: Parental BRIEF questionnaire changes of GEC Tscore over time.

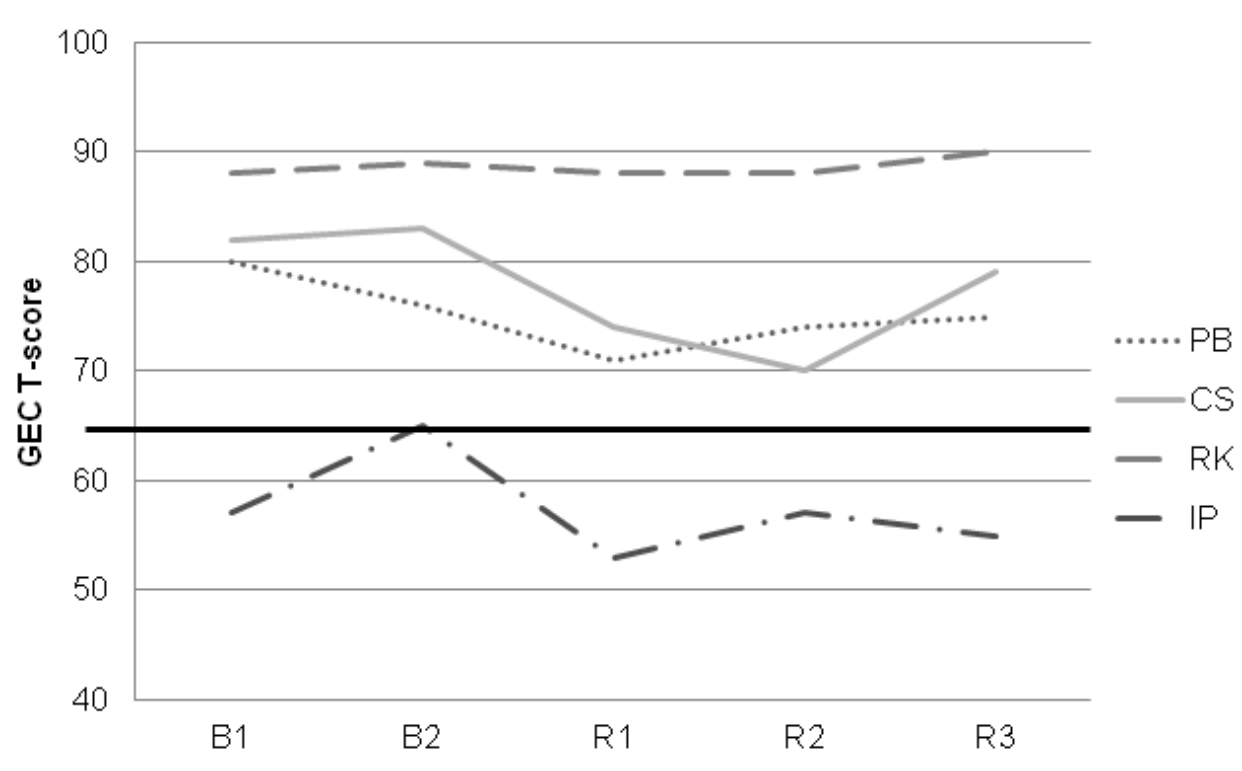

Note: GEC indicates Global Executive Composite.

B1 and B2: first and second baseline assessments; R1, R2, and R3: assessments performed at 0, 3, and 6 months postintervention. The horizontal line represents the clinical cutoff score of 65. 
Figure 4: DEX-C Cognition subscore change over time.

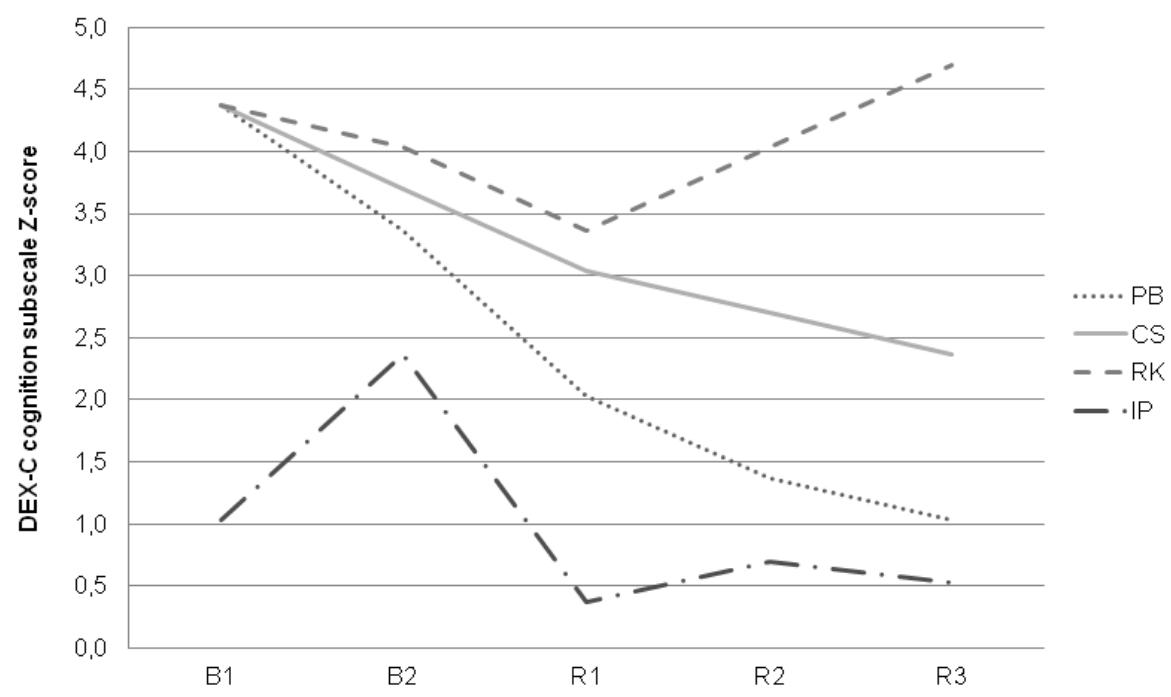

401

Note: B1and B2: first and second baseline assessments; R1, R2, and R3: assessments performed at 0,3 , and 6 months postintervention. DEX-C indicates Dysexecutive Questionnaire for Children.

\section{Generalization: Goal Attainment Scaling and post intervention interview.}

There was a high rate of missing GAS data. GAS could not be developed in collaboration with RK's school everyday people because he attended school very rarely in that period. GAS goals were developed with IP's teacher and school assistant but post intervention GAS forms were handed to IP who lost them (as school closed for 2 months after R1, new forms could not be obtained). CS's teacher, with whom the goals were developed, changed after R1, explaining missing data for R1 and R2. Overall, GAS scales were obtained for at least one "everyday person" per child (see table 3). We were only able to agree on personal goals with one child (RK). The other three viewed the goals proposed by their everyday people as not problematic or not important.

Examples of personal GAS goals corresponding to EFrelated problems reported by everyday people (only the goals and not the full Goal Attainment Scales are reported)

\section{PB - mother :}

-to forget taking antiepileptic drug less often

-to lose fewer objects

-to be flexible enough to change strategy if the first strategy does not work

-to brainstorm for possible solutions before rushing to start a task or school exercise

Examples of general GAS goals
corresponding to metacognitive strategy use
and GMT application (only the goals and not
the full Goal Attainment Scales are reported)
-to be aware of one's "Oops" errors (attentional
slips)
-to detect "Oops" errors as they occur
-to stop and think before beginning a new task
-to formulate a task's main goal before
beginning a task (e.g. school exercise, home
activity..)


PB - school assistant:

-to hand-in homework on time/not so late

-to remember to give routine weekly documents to her mother -to remember non-routine one-off items (e.g. bring money for excursion, ask parents to sign the excursion form..)

CS - mother:

-to estimate if a school exercise will be hard or easy before beginning

-to check school work for errors before handing it in

-to check she has understood what she is supposed to do before beginning a task

-to ask questions if she is not sure she understood what she is supposed to do

CS-teacher:

-to accept the need to check her work when she is prompted to do so

-to estimate the difficulty of exercises/tasks

$\underline{\mathrm{RK}}$ - both parents and the child:

-to be able to tidy up his room (without the need for someone to tell him in which order to do it)

-to be less stressed about his prospective memory problems -to be able to perform an instruction made of 3 consecutive tasks (e.g.: "drink your milk, empty the dish washer and get ready to go out").

IP - teacher and school assistant:

-to be able to prepare schoolbag alone

-to write down information/instructions from teacher without being prompted by school assistant

-to remember to check agenda to see what needs to be done -to write down the things one might forget to do -to remember to look in the note book to perform the intended action -to follow a series of steps that are given to perform a task, finishing each step before moving to another -to split complex tasks into steps and substeps -to check a task/exercise before moving on to another
Table 3: Personal and general GAS goals

All children progressed towards their goals at R1. However, only one of the GAS scores (IP's) reached the

expected goal attainment level (T-score of 50). During the external interview at the end of the study, PB's

mother reported significant daily life benefits of the program: PB forgot her antiepileptic drugs much less often

(by linking her breakfast orange juice with remembering to take her medications), was less often late at school

and made important progress at school allowing her to continue schooling in an ordinary class with a school 
positive outcome were reported for IP by his main carer, which was consistent with a GAS score that reached 50. Parents reported some general progress in well-being at R1 for RK and CS. Most children carried on cooking after the intervention and RK was for the first time allowed to be in the kitchen alone by his parents. Parents reported that children's self-esteem increased because they could make a meal for the family.

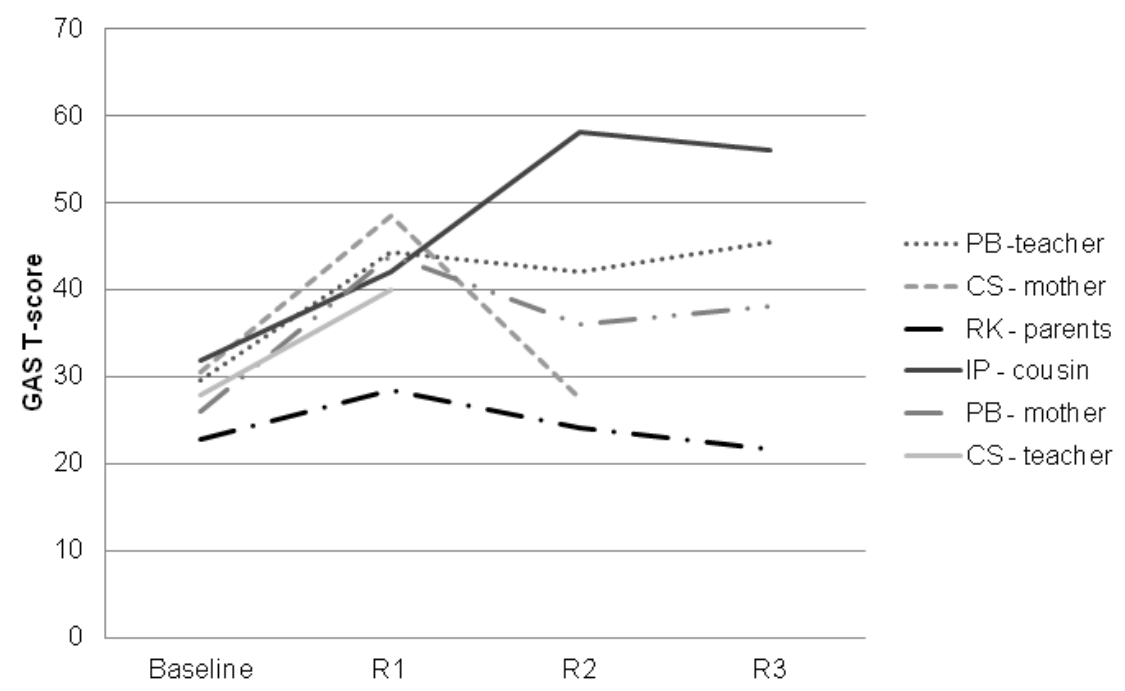

Fig 5 : Goal Attainment Scaling (GAS) T-score evolution over time. Note: R1, R2, R3: assessments performed at 0, 3 and 6 months post-intervention.

Participation of everyday people. Overall, the level of participation of the everyday people was very low.

Mission sheets were very rarely filled in. Only RK's parents asked for feedback after the intervention. In interviews, parents, teachers and school assistants all reported that the intervention was fun for the child and that metacognitive techniques "were useful". However when asked to provide examples of metacognitive strategies contained in the "Cognitive Coaching" guide they had received, seven out of ten everyday people recalled less than half of the strategies. Moreover examples of strategy use were not always appropriate. Between-session assignments (including the simple task of helping the child to detect and write in a table when an "Oops error" had occurred) were never or rarely done. Concrete intervention content was much better followed than the abstract demand of "cognitive coaching": one school assistant (PB's) regularly used the paper 
notebook to compensate for PB's constant PM failures relating to school goals (bring sports clothes, get a form signed), one mother (CS's) started to cook with her daughter. Several parents reported that using the term "Oops error" helped to lower family's tension to the child's cognitive failures and some began using the term with their other children and themselves. All parents reported being generally too busy to apply the cognitive coaching at home. Teachers reported the children did not use the strategies at school, but had not prompted the children to do so. Both teachers and school assistants tended to emphasize the behavioral, attentional and "lack of effort" problems at school as the key problem for the child and did not consider metacognitive strategies use as a priority for the child. A lack of knowledge about TBI was identified with children's difficulties not being seen as cognitive ("he does not try to pay attention", "he has no friends").

\section{DISCUSSION}

The "Context-sensitive GMT" intervention comprised of (1) an adapted Goal Management Training (GMT), (2) metacognitive strategies practice through meaningful activities, (3) a "cognitive coaching guide" for the child's everyday people. The program was feasible to implement and apparently enjoyable for children. However, participation of everyday people was limited. Children significantly improved on the Saint Day Task (time-based prospective memory). EF performance in the ecological Children's Cooking Task (CCT) improved in two children. Three children showed a decrease on parental BRIEF scores reflecting possibly less executive dysfunction in daily life at home. All children decreased their cognition DEX-C sub-score, suggesting that parents perceived improvement in cognitive EF impairment. There were some indications of generalization to untrained tasks in all children, but not sufficient to achieve the expected level of achievement in EF-related GAS goals. When presented with a truly novel task (the parallel version of CCT- "Christmas biscuits"), all children dropped to their initial level of performance indicating a lack of generalization. Intervention effects persisted at threemonth follow-up and were partially maintained at six-month follow-up.

One reason why participation was low for everyday people was that families had difficult situations to deal with (see Table 1), leaving little time for the cognitive coaching of their child. The chronic phase of TBI may not be the optimum time for new cognitive coaching practices to be taught to parents and others, as many habits have already settled. The cognitive coaching guide, although simply explained, was abstract and everyday 
people were not involved in direct training sessions, as opposed to other programs ${ }^{11,66,67}$. The cognitive coaching guide was rarely used by the teachers and school assistants. It is not entirely clear why this was, but one possibility is that the relatively limited contact with the investigators (a phone call before and after the study and the rest through a written guide) was not sufficient to engage them in the intervention contrary to other school-delivered interventions ${ }^{68}$. This is clearly an important issue for future studies and for clinical interventions that depend heavily on a child's everyday people for success. It is probably easier to engage school staff when the interventions are aimed at responding to their needs (especially managing behavior problems such as those reported in Feeney and Ylvisaker studies $\left.{ }^{68}{ }^{69}\right)$. In everyday clinical practice, frequent contact with the child's everyday people (especially school staff) is often not feasible and so examining whether written information (such as our cognitive coaching guide) can facilitate intervention support from these everyday people is an important research question.

The prospective memory (PM) performance might have improved because the task became familiar and routine. However, previous studies with adults using a similar design did not show an improvement of performance with time ${ }^{44}$. Furthermore, children performed so poorly and with so much variation from week to week (very rarely giving the Saint day within one hour of the target time) that no possible routine could have been established. We could not control for the performance of the ongoing task (activity the child was doing at the target time). It has been emphasized that PM performance needs to take into account performance in the ongoing task as well as the PM performance because PM paradigms can be considered as a dual task paradigms ${ }^{23}$. As such it is possible that PM performance increased at the expense of ongoing activities. For one child (RK), his parents actually reported that he stopped all activity up to one hour before the target time, watching the clock in order to perform the task (but often actually forgot the task anyway). Pausing activity to avoid missing an important phone call appointment may be considered an effective strategy in real life, albeit not for an hour beforehand.

Although ratings on the parental BRIEF questionnaire improved, better scores may not have been due to improvement in EF. Rather, it is possible there was some bias in questionnaire responses. For example, parents were involved in the training and their responses may have reflected a desire to be perceived as good cognitive 
coaches. Furthermore, the "home-school cognitive coaching" guide may have increased carers' insight into the child's difficulties, meaning that even if improvements in behavior had occurred these were balanced out with greater awareness of difficulties on the part of the carer. These issues could perhaps explain why the other outcome measures (CCT, GAS) were not consistent with BRIEF scores (e.g. the BRIEF scores of CS and PB decreased but they did not improve on the CCT and whilst RK made best progress on CCT there was no corresponding decrease in BRIEF scores). However, it is possible that metacognitive strategies are effective in a time-limited task such as the Children's Cooking Task (CCT) but impractical in the context of daily life's constant attentional demands, as it is an effortful, top-down process. This may explain why RK made good progress on the CCT, but did not apply the metacognitive strategies in daily life so that parents did not notice a real change in everyday life post-intervention. Alternatively it may be the case that parents and other everyday people may not have had sufficient training to enable them to support the children to implement the strategies in everyday situations consistently. Furthermore, differences between objective measures and improvements reported by parents and patients have been frequently noted ${ }^{70,23}$. Correlations between parental BRIEF scores and EF classical test ${ }^{5,55}$ and with the CCT ${ }^{47}$ are typically small so the BRIEF might not have captured the children's progress. However, all children significantly improved on the DEX-C cognition scores at R1, including IP and RK, which is consistent with earlier finding that the number of errors in CCT and DEX cognition subscales are highly correlated ${ }^{47}$ in both adults ${ }^{71,72}$ and children ${ }^{47}$ and might be a better measure of the children's executive progress than the BRIEF.

For PB it is difficult to explain the contrast between consistency of improvement on DEX-C Cognition subscore, GAS, qualitatively reported generalization, parental BRIEF - and the increased number of errors on CCT. This should however be interpreted with caution because all improvements were based on subjective informant reports, mostly of her mother. As PB seemed to have very poor awareness according to the therapist, the intervention might have improved her awareness rather than EF, which would explain perceived improvement in her natural contexts but not on objective measures of $\mathrm{EF}$ (CCT). Nevertheless she is the child who seems to have benefited most from the intervention, with lasting effects at six months. This was unexpected as lack of insight is known to impede patients from actively engaging in rehabilitation ${ }^{73}$ and is a factor of poorer outcome. Indeed PB never found the sessions "useful", but only "fun". In the absence of awareness, her 
motivation did not seem to be to overcome her difficulties (perceived as non problematic) but rather to enjoy herself during the sessions, and through that enjoyment some implicit learning may have occurred. In children, enjoyment may be more important to an intervention's success than awareness and our intervention seems to have fulfilled this requirement. As Bjorklund noted, "Trying something new may be a goal into itself, and the fact that it does not improve performance may be relatively unimportant to children" ${ }^{74}$. This may be why children were happy to try the metacognitive strategies on paper-and-pencil tasks but showed no consistent application of strategies in the meaningful activities. The same finding has been reported in Missiuna's study ${ }^{66}$ of cognitive strategy training in children with TBI: making the intervention fun was identified as being useful, whereas the "Goal-Plan-Do-Check" strategy (that is similar to GMT) and promotion of good strategy use were not. Considering together the evidence of ours and Missiuna's studies (both on very small samples), it seems that strategy use does not come easily to children with more severe TBI and therefore may not be the best rehabilitation approach for them. In any case, strategies need to be simple, concrete and repeatedly practiced in order to benefit those children.

Usually, elaborating a goal attainment scale (GAS) serves to focus rehabilitation on that goal. Such goal-focused rehabilitation is indeed an effective approach. However this presents a methodological challenge for EFresearch: when a task is trained, its familiarity may make it less demanding on EF as it is likely to require the application of learned knowledge and task-specific procedures (which may have become automatic therefore not "executive"), rather than more general problem solving and goal management processes ${ }^{60,62}$. On the contrary, daily life is full of EF-demanding tasks that require conscious, novel and effortful processing ${ }^{3,60}$, without lapses into automaticity. Apparent progress after a goal-focused training may not necessarily reflect changes in underlying executive processes needed to face daily life. Conversely, our aim was to improve children's ability to cope with new, EF-demanding situations. As an outcome measure needs to be novel

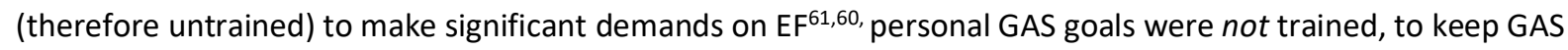
as a generalization measure of EF. However, in future studies it would be more pertinent to divide child's goals into a trained set of goals (and corresponding GAS) and an untrained set of goals (and corresponding GAS) and then to focus the intervention on training the former while using the latter as an ecological generalization measure. In such an approach, main issues would be to match GAS sets for level of difficulty, child's interest 
and level of priority as seen by everyday people who participated in goal selection. Furthermore for GAS aiming at measuring generalization, it would be important to control how much explicit linking to these goals is done during the intervention. The intervention would probably be more effective if it combined goal-focused rehabilitation and general metacognitive training. Elaborating two sets of GAS has already been proposed by Schlosser" in the concept of "control goals". This could have supported further the finding of our study that children could be trained effectively in a meaningful task such as making a chocolate cake (CCT) by combining metacognitive training and repeated cake baking but could not be trained to manage a new untrained recipe (Christmas biscuits). More broadly, in rehabilitation research, using two sets of GAS would make of GAS methodology both a powerful motor for achieving meaningful goals by focusing intervention on them and a pertinent measure of generalization. Future research should also focus on other goal-setting procedures: we did not manage to agree on EF goals with the children in our study, whereas in Missiuna's study ${ }^{66}$, children were able to self-identify goals using a more framed and age-appropriate goal setting system than GAS, which could be used in future studies. However, children in Missiuna's study ${ }^{66}$ had sustained mild to moderate TBI and were probably less impaired. Goal setting requires some basic level of awareness, which children with severe TBI often lack. Lack of awareness was identified for all children in our study except RK and seemed to be the main reason why goals could not be identified by the children. Besides, in Missiuna's study, children were allowed to choose any goal (e.g. learn a new sport) whereas we purposefully retained only EF-related goals. More in-depth assessment of awareness would bring valuable contribution for research on goal-setting procedures.

The intervention was able to improve one particular prospective memory task performed in an ecological setting (SDT), it allowed some children to perform better in a cooking task (CCT) and it resulted in some gains in daily executive functioning. However, this metacognitive training did not allow enough generalization effects to reach expected levels in EF untrained personalized goals or to manage a novel complex EF-demanding task. The aim of providing children with meta-cognitive strategies applicable to "any" situation in life is an ideal goal but is perhaps not feasible: children's ability to cope with new, EF-demanding situations of daily life may not be possible to improve with training in case of severe impairments. In those severe cases, a repeated, goalfocused rehabilitation using activities that are meaningful to the children, and not focusing on explicit 
generalization training, may be a more reasonable therapeutic option (see ${ }^{66}$ for an example of effective goalfocused intervention in a small sample of children with TBI). It should also be emphasized that GMT targets more specifically the PM aspects of EF-demanding tasks and much less problem-solving abilities. This study supports a recent review ${ }^{19}$ in adults which concluded that GMT is probably more effective when combined with other interventions targeting other aspects of EF such as problem solving and initiation (see ${ }^{76,63}$ for examples of such interventions in adults).

Limitations of previously published studies included: insufficient assessment of generalization ${ }^{77}$, of specific effects on $\mathrm{EF}^{78,11}$, lack of objective cognitive performance measures (using questionnaires only as the outcome measure $)^{12}$, use of problem-solving tasks that lack ecological validity ${ }^{79}$, lack of demonstration of EF difficulties prior to intervention ${ }^{45}$ or lack of multiple baseline or follow-up in pre-post designs ${ }^{80,66}$. Others focused mainly on the behavioral aspects of the dysexecutive syndrome ${ }^{68,13}$. This study is to the best of our knowledge the first study that explores whether metacognitive training generalizes and helps children to adapt and manage a novel EF-demanding task and to achieve untrained goals. Of course the small sample of this study does not allow to draw general conclusions about the program efficacy. Our results must be interpreted with caution, especially because we included the most challenging population for this pilot intervention, which may have limited its effectiveness i.e. children with severe EF impairment and with three known major factors of poorer outcome $^{81,57,56,82}$ : (1) severe TBI; (2) sustained at an early age; (3) in non-optimally functioning families (similarly to Corbett's $\mathrm{GMT}^{40}$ that targeted children from low socio-economic background in Cape Town with little success). Those children are usually excluded from protocols ${ }^{66}$ and adult interventions using GMT usually target patients with moderate and mild $\mathrm{TBI}^{20,76}$. As this study demonstrates the feasibility of the program for a particularly complex group of children, it would be helpful to replicate this study with children who have sustained a moderate TBI and children who may have more access to everyday people for providing cognitive coaching. On the other hand, in the clinical setting, it is precisely children with severe TBI and complex family situations that are most needy of intervention and future research should focus on this group, in spite of its challenges. 
For clinical use, the intervention may need further adaptation: the program may benefit from being longer to allow the children to integrate each strategy before practicing a new one, everyday people should be supported further to participate in the sessions, in a similar way to that used in Braga's study ${ }^{11}$. Cognitive coaching should be presented through concrete activities to be done at home and at school rather than general concepts and advice. The intervention should be more closely embedded in the family life in order to improve family participation without adding an additional family burden ${ }^{83,84}$. Not all families are willing and/or capable of engaging in a family-delivered program ${ }^{84}$ and evaluating how to predict this prior to intervention would be of benefit to service providers. Direct contact with school staff is needed. The impact of parental metacognitive knowledge, skills and beliefs on outcomes in family-delivered interventions would also be a valuable component of future studies.

\section{REFERENCES}

1. Anderson P. Assessment and Development of Executive Function (EF) During Childhood. Child Neuropsychology. 2002;8(2):71-82.

2. Gioia GA, Isquith PK. Ecological Assessment of Executive Function in Traumatic Brain Injury. Developmental Neuropsychology. 2004;25(1-2):135-158.

3. Rabbitt P. Methodologies and Models in the study of Executive Function. In: Methodology of Frontal and Executive Functions. East Sussex, UK: Psychology Prass Ltd. P. Rabbitt. Available at: http://www.scribd.com/doc/50671857/Methodology-of-Frontal-and-Executive-Functions. Accessed July 30, 2012.

4. Burgess PW, Simons JS. Theories of frontal lobe executive function: clinical applications. In: The Effectiveness of Rehabilitation for Cognitive Deficits. Oxford: Oxford University Press. Halligan PW and Wade DT; 2005.

5. Babikian T, Asarnow R. Neurocognitive outcomes and recovery after pediatric TBI: meta-analytic review of the literature. Neuropsychology. 2009;23(3):283-296. 
6. Anderson V. Assessing executive functions in children: biological, psychological, and developmental considerations. Developmental Neurorehabilitation. 2001;4(3):119-136.

7. Ross KA, Dorris L, McMillan T. A systematic review of psychological interventions to alleviate cognitive and psychosocial problems in children with acquired brain injury. Dev Med Child Neurol. 2011;53(8):692-701.

8. Limond J, Leeke R. Practitioner Review: Cognitive rehabilitation for children with acquired brain injury. Journal of Child Psychology and Psychiatry. 2005;46(4):339-352.

9. Slomine B, Locascio G. Cognitive rehabilitation for children with acquired brain injury. Developmental Disabilities Research Reviews. 2009;15(2):133-143.

10. Ylvisaker M, ed. Traumatic brain injury rehabilitation: Children and adolescents (2nd ed.). Woburn, MA, US: Butterworth-Heinemann; 1998.

11. Braga LW, da Paz Júnior AC, Ylvisaker M. Direct clinician-delivered versus indirect family-supported rehabilitation of children with traumatic brain injury: A randomized controlled trial. Brain Injury. $2005 ; 19(10): 819-831$.

12. Wade SL, Walz NC, Carey J, Williams KM, Cass J, Herren L, Mark E, Yeates KO. A randomized trial of teen online problem solving for improving executive function deficits following pediatric traumatic brain injury. J Head Trauma Rehabil. 2010;25(6):409-415.

13. Wade SL, Walz NC, Carey J, McMullen KM, Cass J, Mark E, Yeates KO. Effect on behavior problems of teen online problem-solving for adolescent traumatic brain injury. Pediatrics. 2011;128(4):e947-953.

14. Ylvisaker M, Adelson PD, Braga LW, Burnett SM, Glang A, Feeney T, Moore W, Rumney P, Todis B. Rehabilitation and ongoing support after pediatric TBI: twenty years of progress. J Head Trauma Rehabil. 2005;20(1):95-109. 
15. Cicerone KD, Langenbahn DM, Braden C, Malec JF, Kalmar K, Fraas M, Felicetti T, Laatsch L, Harley JP, Bergquist T, Azulay J, Cantor J, Ashman T. Evidence-Based Cognitive Rehabilitation: Updated Review of the Literature From 2003 Through 2008. Archives of Physical Medicine and Rehabilitation. 2011;92(4):519-530.

16. Butler RW, Copeland DR, Fairclough DL, Mulhern RK, Katz ER, Kazak AE, Noll RB, Patel SK, Sahler OJZ. A multicenter, randomized clinical trial of a cognitive remediation program for childhood survivors of a pediatric malignancy. Journal of Consulting and Clinical Psychology. 2008;76(3):367-378.

17. Chan DYK, Fong KNK. The effects of problem-solving skills training based on metacognitive principles for children with acquired brain injury attending mainstream schools: a controlled clinical trial. Disabil Rehabil. 2011;33(21-22):2023-2032.

18. Levine B, Robertson IH, Clare L, Carter G, Hong J, Wilson BA, Duncan J, Stuss DT. Rehabilitation of executive functioning: an experimental-clinical validation of goal management training. J Int Neuropsychol Soc. 2000;6(3):299-312.

19. Krasny-Pacini A, Chevignard M, Evans J. Goal Management Training for rehabilitation of executive functions: a systematic review of effectivness in patients with acquired brain injury. 2013. Available at: http://informahealthcare.com/eprint/ijeZAnewNg5hUQWaYuny/full. Accessed April 18, 2013.

20. Levine B, Schweizer TA, O'Connor C, Turner G, Gillingham S, Stuss DT, Manly T, Robertson IH. Rehabilitation of Executive Functioning in Patients with Frontal Lobe Brain Damage with Goal Management Training. Front Hum Neurosci. 2011;5. Available at: http://www.ncbi.nlm.nih.gov/pmc/articles/PMC3043269/. Accessed July 27, 2012.

21. Duncan J, Emslie H, Williams P, Johnson R, Freer C. Intelligence and the Frontal Lobe: The Organization of Goal-Directed Behavior. Cognitive Psychology. 1996;30(3):257-303.

22. Duncan J, Johnson R, Swales M, Freer C. Frontal lobe deficits after head injury: Unity and diversity of function. Cognitive Neuropsychology. 1997;14(5):713-741. 
23. Fish J, Wilson BA, Manly $\mathrm{T}$. The assessment and rehabilitation of prospective memory problems in people with neurological disorders: A review. Neuropsychol Rehabil. 2010;20(2):161-179.

24. Okuda J, Fujii T, Yamadori A, Kawashima R, Tsukiura T, Fukatsu R, Suzuki K, Ito M, Fukuda H.

Participation of the prefrontal cortices in prospective memory: evidence from a PET study in humans. Neurosci Lett. 1998;253(2):127-130.

25. Burgess PW, Gonen-Yaacovi G, Volle E. Functional neuroimaging studies of prospective memory: what have we learnt so far? Neuropsychologia. 2011;49(8):2246-2257.

26. Mackinlay RJ, Kliegel M, Mäntylä T. Predictors of time-based prospective memory in children. Journal of Experimental Child Psychology. 2009;102(3):251-264.

27. Mahy CEV, Moses LJ. Executive functioning and prospective memory in young children. Cognitive Development. 2011;26(3):269-281.

28. Ford RM, Driscoll T, Shum D, Macaulay CE. Executive and theory-of-mind contributions to event-based prospective memory in children: exploring the self-projection hypothesis. J Exp Child Psychol. 2012;111(3):468489.

29. Kerns KA. The CyberCruiser: an investigation of development of prospective memory in children. J Int Neuropsychol Soc. 2000;6(1):62-70.

30. Ward H, Shum D, Dick B, McKinlay L, Baker-Tweney S. Interview study of the effects of paediatric traumatic brain injury on memory. Brain Injury. 2004;18(5):471-495.

31. McCauley SR, McDaniel MA, Pedroza C, Chapman SB, Levin HS. Incentive effects on event-based prospective memory performance in children and adolescents with traumatic brain injury. Neuropsychology. 2009;23(2):201-209.

32. Ward H, Shum D, McKinlay L, Baker S, Wallace G. Prospective Memory and Pediatric Traumatic Brain Injury: Effects of Cognitive Demand. Child Neuropsychology. 2007;13(3):219-239.

JHTR pGMT 2013 
33. McCauley SR, Levin HS. Prospective Memory in Pediatric Traumatic Brain Injury: A Preliminary Study. Developmental Neuropsychology. 2004;25(1-2):5-20.

34. McCauley SR, Pedroza C, Chapman SB, Cook LG, Vásquez AC, Levin HS. Monetary incentive effects on event-based prospective memory three months after traumatic brain injury in children. J Clin Exp Neuropsychol. 2011;33(6):639-646.

35. Wechsler D. WISC-IV: échelle d'intelligence de Wechsler pour enfants : manuel d'interprétation. ECPA Les Ed. du Centre de psychologie appliquée; 2005.

36. Cohen M. Echelle de Mémoire pour Enfants. Les éditions du centre de psychologie appliquée.; 2001.

37. Roy A, Roulin J-L, Le Gall D, Fournier N, Groupe FEE. Fonctions Exécutives chez l'Enfant. unpublished

38. Crawford J.R., Garthwaite P.H. Investigation of the single case in neuropsychology: confidence limits on the abnormality of test scores and test score differences. Neuropsychologia. 2002;40(8):1196-1208.

39. Crawford JR, Howell DC. Comparing an Individual's Test Score Against Norms Derived from Small Samples. The Clinical Neuropsychologist. 1998;12(4):482-486.

40. Corbett C, Schrieff L, Thomas K. Rehabilitation of executive functioning following pediatric traumatic brain injury: a goal management training intervention. 2009.

41. Toglia J, Johnston MV, Goverover Y, Dain B. A multicontext approach to promoting transfer of strategy use and self regulation after brain injury: An exploratory study. Brain Inj. 2010;24(4):664-677.

42. Perdices M, Tate RL. Single-subject designs as a tool for evidence-based clinical practice: Are they unrecognised and undervalued? Neuropsychol Rehabil. 2009;19(6):904-927.

43. Graham JE, Karmarkar AM, Ottenbacher KJ. Small Sample Research Designs for Evidence-Based Rehabilitation: Issues and Methods. Archives of Physical Medicine and Rehabilitation. 2012;93(8):S111-S116. 
44. Fish J, Evans JJ, Nimmo M, Martin E, Kersel D, Bateman A, Wilson BA, Manly T. Rehabilitation of executive dysfunction following brain injury: "Content-free" cueing improves everyday prospective memory performance. Neuropsychologia. 2007;45(6):1318-1330.

45. Rous R, Adams M, Fish J, Adlam A. Prospective Memory Intervention for adolescents with acquired brain injury: a preleminary study. In: Edinburgh; 2012.

46. Chevignard MP, Soo C, Galvin J, Catroppa C, Eren S. Ecological assessment of cognitive functions in children with acquired brain injury: A systematic review. Brain Inj. 2012;26(9):1033-1057.

47. Chevignard MP, Catroppa C, Galvin J, Anderson V. Development and Evaluation of an Ecological Task to Assess Executive Functioning Post Childhood TBI: The Children's Cooking Task. Brain Impairment. 2010;11(02):125-143.

48. Chevignard MP, Servant V, Mariller A, Abada G, Pradat-Diehl P, Laurent-Vannier A. Assessment of executive functioning in children after TBI with a naturalistic open-ended task: A pilot study. Developmental Neurorehabilitation. 2009;12(2):76-91.

49. Servant V, Chevignard M. Evaluation ecologique des fonctions cognitives chez les enfants et adolescents traumatisés crâniens à travers une tâche de la vie quotidienne: réalisation d’une activité de cuisine. (unpublished thesis). 2009.

50. Gioia GA, Isquith PK, Guy SC, Kenworthy L. Behavior Rating Inventory of Executive Function ${ }^{\circledR}\left(\right.$ BRIEF $\left.^{\circledR}\right)$. 2000.

51. Gioia GA, Isquith PK, Guy SC, Kenworthy L. Behavior Rating Inventory of Executive Function ${ }^{\circledR}\left(B R I E F^{\circledR}\right)$. Adaptation française A. Roy, N. Fournet, D. Legall, J-L Roulin. Hogrefe; 2000.

52. Emslie H. Behavioural Assessment of the Dysexecutive Syndrome for Children: (BADS-C). Thames Valley Test Company; 2003. 
53. Gioia GA, Isquith PK, Guy SC, Kenworthy L. TEST REVIEW Behavior Rating Inventory of Executive Function. Child Neuropsychology. 2000;6(3):235-238.

54. Anderson VA, Anderson P, Northam E, Jacobs R, Mikiewicz O. Relationships Between Cognitive and Behavioral Measures of Executive Function in Children With Brain Disease. Child Neuropsychology. $2002 ; 8(4): 231-240$.

55. Vriezen ER, Pigott SE. The Relationship Between Parental Report on the BRIEF and Performance-Based Measures of Executive Function in Children with Moderate to Severe Traumatic Brain Injury. Child Neuropsychology. 2002;8(4):296-303.

56. Nadebaum C, Anderson V, Catroppa C. Executive function outcomes following traumatic brain injury in young children: a five year follow-up. Dev Neuropsychol. 2007;32(2):703-728.

57. Mangeot S, Armstrong K, Colvin AN, Yeates KO, Taylor HG. Long-Term Executive Function Deficits in Children With Traumatic Brain Injuries: Assessment Using the Behavior Rating Inventory of Executive Function (BRIEF). Child Neuropsychology. 2002;8(4):271-284.

58. Kiresuk TJ, Sherman R. Goal Attainment Scaling: A general method for evaluating comprehensive community mental health programs. Comm Mental Health J. 1968;4(6):443-453.

59. Krasny-Pacini A, Hiebel J, Pauly F, Godon S, Chevignard M. Goal Attainment Scaling in rehabilitation: A literature-based update. Annals of Physical and Rehabilitation Medicine. 2013;56(3):212-230.

60. Denckla MB. Measurement of executive function. In: Frames of reference for the assessment of learning disabilities: New views on measurement issues. Baltimore, MD, US: Paul H Brookes Publishing; 1994:117-142.

61. Shallice T, Burgess P. Higher order cognitive impairments and frontal lobelesions in man. In: Frontal lobe function and dysfunction. New York: Oxford University Press. In: Levin HS and Benton AL; 1991:125- 138. 
62. Philips L. Do "frontal tests" measure executive function? Issues of assessment and evidence from fluency tests. In: Methodology of Frontal and Executive Functions. UK: Psychology PressLtd. Rabbitt P.; 1997:200-203.

63. Spikman JM, Boelen DHE, Lamberts KF, Brouwer WH, Fasotti L. Effects of a multifaceted treatment program for executive dysfunction after acquired brain injury on indications of executive functioning in daily life. J Int Neuropsychol Soc. 2010;16(1):118-129.

64. Parker RI, Vannest K. An improved effect size for single-case research: nonoverlap of all pairs. Behav Ther. 2009;40(4):357-367.

65. Cohen J. Statistical Power Analysis for the Behavioral Sciences, Second Edition. Routledge; 1988.

66. Missiuna C, DeMatteo C, Hanna S, Mandich A, Law M, Mahoney W, Scott L. Exploring the Use of Cognitive Intervention for Children with Acquired Brain Injury. Physical \& Occupational Therapy in Pediatrics. 2010;30(3):205-219.

67. Tamm L, Nakonezny PA, Hughes CW. An Open Trial of a Metacognitive Executive Function Training for Young Children With ADHD. Journal of attention disorders. 2012. Available at: http://www.ncbi.nIm.nih.gov/pubmed/22647287. Accessed August 23, 2012.

68. Feeney TJ, Ylvisaker M. Context-sensitive behavioral supports for young children with TBI: short-term effects and long-term outcome. J Head Trauma Rehabil. 2003;18(1):33-51.

69. Feeney TJ. Structured flexibility: the use of context-sensitive self-regulatory scripts to support young persons with acquired brain injury and behavioral difficulties. J Head Trauma Rehabil. 2010;25(6):416-425.

70. Lewis MW, Babbage DR, Leathem JM. Assessing executive performance during cognitive rehabilitation. Neuropsychol Rehabil. 2011;21(2):145-163.

71. Chevignard M, Pillon B, Pradat-DiehI P, Taillefer C, Rousseau S, Le Bras C, Dubois B. An ecological approach to planning dysfunction: script execution. Cortex. 2000;36(5):649-669. 

dysexecutive syndrome using execution of a cooking task. Neuropsychol Rehabil. 2008;18(4):461-485.

73. Ownsworth T, Clare L. The association between awareness deficits and rehabilitation outcome following acquired brain injury. Clinical Psychology Review. 2006;26(6):783-795.

74. Bjorklund DF. Learning to think on their own: executive function, strategies and problem-solving. In: Children's Thinking: Cognitive Development and Individual Differences. Cengage Learning; 2011:270.

75. Schlosser RW. Goal attainment scaling as a clinical measurement technique in communication disorders: a critical review. J Commun Disord. 2004;37(3):217-239.

76. Miotto EC, Evans JJ, Souza de Lucia MC. Rehabilitation of executive dysfunction: A controlled trial of an attention and problem solving treatment group. Neuropsychological Rehabilitation. 2009;19(4):517-540.

77. Selznick L, Savage RC. Using self-monitoring procedures to increase on-task behavior with three adolescent boys with brain injury. Behavioral Interventions. 2000;15(3):243-260.

78. Walker AJ, Onus M, Doyle M, Clare J, McCarthy K. Cognitive rehabilitation after severe traumatic brain injury: A pilot programme of goal planning and outdoor adventure course participation. Brain Injury. December;19(14):1237-1241.

79. Suzman KB, Morris RD, Morris MK, Milan MA. Cognitive-behavioral remediation of problem solving deficits in children with acquired brain injury. Journal of Behavior Therapy and Experimental Psychiatry. 1997;28(3):203-212.

80. Catroppa C, Anderson V, Muscara F. Rehabilitation of executive skills post-childhood traumatic brain injury (TBI): A pilot intervention study. Developmental Neurorehabilitation. 2009;12(5):361-369.

81. Donders J, Warschausky S. Neurobehavioral Outcomes After Early Versus Late Childhood Traumatic Brain Injury. Journal of Head Trauma Rehabilitation. 2007;22(5):296-302. 
Brain Injury in Young Children: A Preliminary Analysis. Developmental Neuropsychology. 2004;26(1):487-512.

83. Cole WR, Paulos SK, Cole CAS, Tankard C. A review of family intervention guidelines for pediatric

acquired brain injuries. Dev Disabil Res Rev. 2009;15(2):159-166.

84. Jansen LM, Ketelaar M, Vermeer A. Parental experience of participation in physical therapy for

Examples of how metacognitive strategies were applied and used in theoretical modules, meaningful activities and suggested activities for everyday people.

\begin{tabular}{|l|l|l|l|}
\hline $\begin{array}{l}\text { Metacognitive } \\
\text { strategy }\end{array}$ & $\begin{array}{l}\text { Theoretical module } \\
\text { exercise }\end{array}$ & Meaningful activity & $\begin{array}{l}\text { Cognitive coaching guide } \\
\text { (proposal of situations the } \\
\text { strategy can be applied to): }\end{array}$ \\
\hline $\begin{array}{l}\text { "Stop and State } \\
\text { your goal" }\end{array}$ & $\begin{array}{l}\text { Multi-element tasks } \\
\text { with changing aims } \\
\text { (do some of each sub } \\
\text { task OR earn as many } \\
\text { points as possible) }\end{array}$ & $\begin{array}{l}\text { Cooking biscuits from a } \\
\text { recipe containing prompts } \\
\text { (cartoon character showing a } \\
\text { stop sign) to stop and state } \\
\text { what the goal of the step is } \\
\text { before proceeding }\end{array}$ & $\begin{array}{l}\text { State your goal before beginning } \\
\text { a school exercise. } \\
\text { Use the cartoon character } \\
\text { whenever the child starts an } \\
\text { exercise without understanding } \\
\text { the aim instead of telling him/her } \\
\text { s/he read it wrong. }\end{array}$ \\
\hline "Write the steps" & $\begin{array}{l}\text { Imagining you prepare } \\
\text { a sandwich } \\
\text { Mathematical } \\
\text { problem } \\
\text { Scripts about } \\
\text { organizing a birthday } \\
\text { party }\end{array}$ & $\begin{array}{l}\text { Preparing a cake from an } \\
\text { unordered recipe, presented } \\
\text { without steps and without } \\
\text { details about cooking } \\
\text { procedure }\end{array}$ & $\begin{array}{l}\text { School essay preparation } \\
\text { Organizing homework for the } \\
\text { week } \\
\text { Planning a party/ an outing with } \\
\text { the family }\end{array}$ \\
\hline
\end{tabular}

Eleven general GAS items for metacognitive strategy use and GMT application to daily life were created. These were sent to parents, teachers, school assistants and any other "everyday people". For each item, everyday people had to circle the level corresponding best to the child's actual performance relating to the goal, ranging from -2 (worse performance they 
could imagine) to +2 (best expected performance), 0 corresponding to the most likely performance expected after intervention.

E.g.: "XX (child name) writes on his own initiative things he/she might forget to do in a single and well-identified note-book or planner (excluding homework he/she is explicitly asked to write down by the teacher)»

\section{$-2:$ never}

\section{-1 : sometimes but it is not regular or functional enough to rely on it}

0 : Writes down important things to be done but you need to emphasize/repeat it is an important thing to remember to do

$+1:$ The important things are written without you telling the child it is important to remember +2 : Writes all the things and without you telling the child to remember to do so

The answers to this first GAS questionnaire allowed readjustment of the scales, through the following rules: (1) Scales scoring +1 or +2 pre-intervention were removed as the performance for the item was satisfactory without intervention and the item was therefore not a goal to attain. (2) Scales that scored 0 were reformulated in order to have the preintervention level corresponding to -1 by fixing a more challenging $0,+1$ and +2 scores (this was particularly the case for older children). (3) Scales scoring -2 or -1 were not reformulated, in order to capture a possible worsening in performance for those having -1 as the preintervention level. Therefore the initially identical scales were readjusted according to the child's present performance relating to each metacognitive strategy use goal.

In order to fulfill the unidimensionality criteria, some goals relating to strategy use were split into two goals (e.g.: effective use of a paper note-book to compensate for PM failures was split into (1) writing down the things one might forget to do; (2) remember to look into the note book to perform the intended action). These goals were considered important goals by the researchers but did not take into account the personal goals of the child and his everyday people.

\section{Writing procedure for personal GAS corresponding to EF-related problems reported by everyday people.}

Two to seven additional personal GAS per child were created based on parents', teacher's and school assistant's concerns. Goals were selected after analyzing the BRIEF and DEX-C questionnaires and after a one- to two-hour interview with parents and a phone interview with the teacher and/or school assistant. The first author created the GAS scales in a written form and sent them to the person the goal had been proposed by. The first answers to these personal GAS allowed, if needed, to reformulate the levels according to the same procedure as for the general GAS described above. .

All the scales, including those reformulated were sent again to the everyday people in order to check that the initial level had been worded correctly and corresponded to -2 or -1 prior to intervention. This personalized second GAS set of answers was used to calculate a pre- 
847 intervention T-score and to measure outcome at R1, R2 and R3. Because the procedure

848 required writing, reformulating and double checking for initial level, only one baseline could 849 be calculated for GAS.

850

851

852 


\begin{tabular}{|c|c|c|c|c|c|}
\hline & PB & CS & RK & IP & YR \\
\hline Sex & Girl & Girl & Boy & Boy & Boy \\
\hline Age at inclusion (years) & 11 & 11 & 13 & 8 & 14 \\
\hline TBI mechanism & MVA (passenger) & $\begin{array}{l}\text { Fall of metal bar on } \\
\text { the child's head }\end{array}$ & $\begin{array}{l}\text { MVA (pedestrian hit } \\
\text { by car) }\end{array}$ & $\begin{array}{l}\text { Fall of furniture on the } \\
\text { child's head }\end{array}$ & $\begin{array}{l}\text { Collision against } \\
\text { running child }\end{array}$ \\
\hline Age at injury (years) & 2.5 & 6.5 & 7 & 5.5 & 2.5 \\
\hline Initial GCS & 6 & 4 & 3 & 6 & $<7$ \\
\hline Brain imaging & $\begin{array}{l}\text { Large right } \\
\text { hemisphere } \\
\text { hemorrhage and } \\
\text { edema, right parietal } \\
\text { depression fracture } \\
\end{array}$ & $\begin{array}{l}\text { Cerebellar and right } \\
\text { parieto-occipital } \\
\text { lesion with } \\
\text { depression fracture }\end{array}$ & $\begin{array}{l}\text { Subdural hematoma } \\
\text { with diffuse edema } \\
\text { and pneumocephalus }\end{array}$ & $\begin{array}{l}\text { Brain stem hemorrhage, } \\
\text { Diffuse subarachnoid } \\
\text { hemorrhage }\end{array}$ & Unknown \\
\hline Duration of coma (days) & Unknown & 1 & 10 & 6 & Unknown \\
\hline $\begin{array}{l}\text { Time since injury } \\
\text { (years) }\end{array}$ & 9 & 5 & 6 & 3 & 11 \\
\hline Schooling & $\begin{array}{l}\text { Ordinary school + part- } \\
\text { time SA }\end{array}$ & $\begin{array}{l}\text { Part-time special - } \\
\text { part-time ordinary } \\
\text { schooling }\end{array}$ & $\begin{array}{l}\text { Part -time private } \\
\text { schooling with SA, } \\
\text { part time private } \\
\text { lessons }\end{array}$ & $\begin{array}{l}\text { Ordinary school + part- } \\
\text { time SA }\end{array}$ & $\begin{array}{l}\text { Special schooling } \\
\text { Excluded from } \\
\text { school half of the } \\
\text { year for behavioral } \\
\text { issues }\end{array}$ \\
\hline $\begin{array}{l}\text { Associated } \\
\text { impairments, reported } \\
\text { in medical records and } \\
\text { previous } \\
\text { neuropsychological } \\
\text { assessments }\end{array}$ & $\begin{array}{l}\text { Lack of awareness } \\
\text { Epilepsy absences } \\
\text { treated by } \\
\text { carbamazepine }\end{array}$ & $\begin{array}{l}\text { FSIQ } 69 \\
\text { Impaired ToM and } \\
\text { language } \\
\text { pragmatics } \\
\text { Moderately spastic } \\
\text { equinus foot }\end{array}$ & $\begin{array}{l}\text { Attention problems } \\
\text { Left arm weakness }\end{array}$ & ADHD & $\begin{array}{l}\text { Severe behavioral } \\
\text { disorder } \\
\text { Lack of awareness }\end{array}$ \\
\hline Glasgow Outcome Scale & 2 & 3 & 3 & 2 & 3 \\
\hline Family structure & Monoparental & $\begin{array}{l}\text { Parents separated } \\
\text { geographically, } \\
\text { Sister followed-up for } \\
\text { a transplant }\end{array}$ & $\begin{array}{l}\text { Large family (10 } \\
\text { siblings) }\end{array}$ & $\begin{array}{l}\text { Monoparental family } \\
\text { Father in prison } \\
\text { Primary caregiver: cousin }\end{array}$ & $\begin{array}{l}\text { Two parent } \\
\text { household }\end{array}$ \\
\hline
\end{tabular}




\begin{tabular}{|c|c|c|c|c|c|}
\hline $\begin{array}{l}\text { Parental education } \\
\text { (years) }\end{array}$ & $\begin{array}{l}\text { father : } 14 \\
\text { mother : } 15\end{array}$ & $\begin{array}{l}\text { father : } 11 \\
\text { mother : } 11\end{array}$ & $\begin{array}{l}\text { father : } 22 \\
\text { mother : } 15\end{array}$ & $\begin{array}{l}\text { father : } 7 \\
\text { mother : } 11\end{array}$ & $\begin{array}{l}\text { father : } 4 \\
\text { mother : } 17\end{array}$ \\
\hline
\end{tabular}

\section{Table 1: Characteristics of the participants}

Note: MVA: Motor Vehicle Accident; GCS: Glasgow Coma Scale score; SA: School Assistant; ToM: Theory of Mind; FSIQ: Full Scale Intellectual Quotient; ADHD: Attention Deficit - Hyperactivity Disorder

Note: Full names of traditional paper and pencil tests: WISC: Wechsler Intelligence Scale for Children; BADS-C: Behavioural Assessment of the Dysexecutive Syndrome for Children; CMS: Children's Memory Scale 


\begin{tabular}{|c|c|c|c|c|}
\hline & $\begin{array}{l}\text { Processing speed } \\
\text { (Stroop part 1: } \\
\text { color naming in } \\
\text { seconds) }\end{array}$ & $\begin{array}{l}\text { Inhibitiory Control } \\
\text { (Stroop } \\
\text { interference condition: } \\
\text { number of } \\
\text { uncorrected errors) }\end{array}$ & $\begin{array}{l}\text { Flexibility } \\
\text { (Barre-Joe }{ }^{* *} \text { : } \\
\text { time in seconds) }\end{array}$ & $\begin{array}{l}\text { Planning (Labyrinths: } \\
\text { number of errors) }\end{array}$ \\
\hline PB & $105^{*}$ & 3 & $405^{*}$ & 5* \\
\hline Controls $(n=9)$ & $77,56 \pm 10,50$ & $1,11 \pm 1,17$ & $264,11 \pm 57,20$ & $0,9 \pm 1,00$ \\
\hline CS & $103^{*}$ & 6* & 356 & 5* \\
\hline Controls $(n=7)$ & $70,4 \pm 39,29$ & $1,33 \pm 2,07$ & $338,29 \pm 175,54$ & $0,7 \pm 0,73$ \\
\hline RK & 83 & $4 *$ & 380 & $8^{*}$ \\
\hline Controls $(n=14)$ & $71,50 \pm 10,14$ & $1,00 \pm 1,30$ & $248,14 \pm 51,03$ & $0,9 \pm 1,63$ \\
\hline IP & 99 & $4 *$ & $613^{*}$ & $7^{*}$ \\
\hline Controls $(n=13)$ & $100,38 \pm 35,88$ & $1,46 \pm 1,51$ & $416,83 \pm 95,96$ & $1,2 \pm 1,28$ \\
\hline YR & 69 & 15 & $314^{*}$ & $19 *$ \\
\hline Controls $(n=14)$ & $71,50 \pm 10,14$ & $1,00 \pm 1,30$ & $248,14 \pm 51,03$ & $0,9 \pm 1,63$ \\
\hline $\begin{array}{l}{ }^{*} \mathbf{p}<\mathbf{0 , 0 5} \\
* * \text { Barre Joe cons } \\
\text { only by leg and a }\end{array}$ & $\begin{array}{l}\text { crossing } 46 \text { "Joe" } \\
\text { sition }\end{array}$ & racters on an A3 sheet & taining $240 \mathrm{sim}$ & characters differing \\
\hline
\end{tabular}

Table 1 bis: Childhood Executive Function Battery (FEE) raw scores for participants and their age-, sex- and socio-economic status-matched controls. 


\begin{tabular}{|c|c|c|c|c|c|c|c|c|}
\hline & $\begin{array}{l}\text { WISC IV } \\
\text { matrices }\end{array}$ & $\begin{array}{l}\text { WISC IV } \\
\text { vocabulary }\end{array}$ & $\begin{array}{l}\text { 6 part } \\
\text { test } \\
\text { BADS-C }\end{array}$ & $\begin{array}{l}\text { CMS stories - } \\
\text { immediate }\end{array}$ & $\begin{array}{l}\text { CMS stories- } \\
\text { delayed }\end{array}$ & $\begin{array}{l}\text { CMS backward } \\
\text { span }\end{array}$ & $\begin{array}{l}\text { CMS words list - } \\
\text { immediate }\end{array}$ & $\begin{array}{l}\text { CMS words list - } \\
\text { delayed }\end{array}$ \\
\hline $\mathrm{CS}$ & 7 & 5 & 7 & 8 & 7 & 8 & 12 & 7 \\
\hline$\overline{\mathbf{R K}}$ & 16 & 7 & 8 & 4 & 4 & 10 & 12 & 16 \\
\hline
\end{tabular}

Table 1 ter: Standard scores for traditional paper and pencil tests

Note: WISC: Wechsler Intelligence Scale for Children; BADS-C: Behavioural Assessment of the Dysexecutive Syndrome for Children; CMS: Children's Memory Scale 